This is the final peer-reviewed accepted manuscript of:

Nicolai, M. Zanuccoli, F. Feldmann, M. Hermle and C. Fiegna

"Analysis of Silicon Solar Cells With Poly-Si/SiOx Carrier-Selective Base and Emitter Contacts"

in IEEE Journal of Photovoltaics, vol. 8, no. 1, pp. 103-109, Jan. 2018

The final published version is available online at:

https://doi.org/10.1109/JPHOTOV.2017.2775142

Rights / License:

The terms and conditions for the reuse of this version of the manuscript are specified in the publishing policy. For all terms of use and more information see the publisher's website.

This item was downloaded from IRIS Università di Bologna (https://cris.unibo.it/)

When citing, please refer to the published version. 


\title{
Analysis of Silicon Solar Cells With Poly-Si/SiO Carrier-Selective Base and Emitter Contacts
}

\author{
Massimo Nicolai, Mauro Zanuccoli, Frank Feldmann, Martin Hermle, and Claudio Fiegna
}

\begin{abstract}
Passivating contacts are a promising technology to enhance silicon solar cells conversion efficiency. In this paper, we present a simulation study carried out by using physical models calibrated on the basis of experimental data, aimed at understanding the electrical properties of front emitter silicon solar cells featuring top/rear poly-Si/SiO ${ }_{x}$ selective contacts. Furthermore, we propose a rear junction (RJ) design that desensitizes the fill factor to top electrode resistivity. According to our simulations, the RJ scheme addresses the possibility to omit the transparent conductive oxide allowing promising conversion efficiency of silicon solar cells with carrier-selective contacts. In addition, the influence of the surface recombination velocity at the $\mathrm{c}-\mathrm{Si} / \mathrm{SiO}_{\mathrm{x}}$ interfaces and of the effective tunneling masses is investigated.
\end{abstract}

Index Terms-Numerical simulation, passivating contacts, poly$\mathrm{Si} / \mathrm{SiO}_{\mathrm{x}}$, silicon solar cells.

\section{INTRODUCTION}

$\mathbf{S}$ ILICON solar cell efficiency has been pushed markedly in the last decade. Heterojunction solar cells (SHJs) [1] and passivating contacts based on a thin oxide and a doped silicon layer (tunnel oxide passivated contact - TOPCon) [2], [3] are among the more effective options to enhance the open-circuit voltage $\left(V_{\mathrm{OC}}\right)$ well above $700 \mathrm{mV}$, by notably reducing surface recombination, outclassing point-contact schemes.

Best performing SHJs enable high $V_{\mathrm{OC}}$ (around $745 \mathrm{mV}$ ), thanks to an excellent surface passivation quality, allowing high conversion efficiency [4]. In [5], an SHJ is proposed that guarantees satisfactory electrical properties, by adopting a front transparent conductive oxide (TCO) electrode, ensuring a good contact formation to the amorphous-silicon (a-Si) front contact and providing sufficient lateral conductivity. However, SHJs exhibit considerable drawbacks: 1) the limited thermal budget imposed by the a-Si:H passivation to the metallization process step and 2) TCO increases the overall production cost [6]. Solar cells featuring TOPCon or poly-Si/SiO ${ }_{x}$ [2], [3] may be considered

Manuscript received September 13, 2017; revised October 27, 2017; accepted November 7, 2017. The work was supported in part by the European Union Horizon2020 Research and Innovation Program under the Grant 727529 (DISC Project). (Corresponding author: Massimo Nicolai.)

M. Nicolai, M. Zanuccoli, and C. Fiegna are with the Advanced Research Center of Electronic Systems, University of Bologna, Cesena 47521, Italy (e-mail: massimo.nicolai3@unibo.it; mauro.zanuccoli@unibo.it; claudio. fiegna@unibo.it).

F. Feldmann and M. Hermle are with the Fraunhofer Institute for Solar Energy Systems, Freiburg 79110, Germany (e-mail: frank.feldmann@ise.fraunhofer.de; martin.hermle@ise.fraunhofer.de).

Color versions of one or more of the figures in this paper are available online at http://ieeexplore.ieee.org.

Digital Object Identifier 10.1109/JPHOTOV.2017.2775142

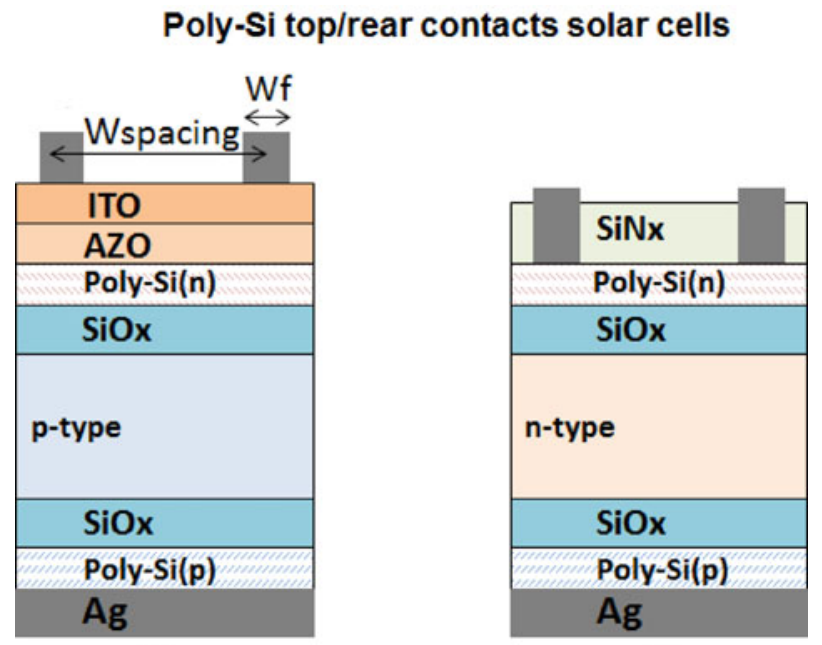

(a)

(b)

Fig. 1. Sketches of the solar cell designs considered in this paper. In (a), the scheme of the fabricated p-type poly-Si top/rear contacts solar cell [9] is shown In (b), the n-type solar cell (rear junction design RJ) with a passivation $\mathrm{SiN}_{\mathrm{x}}$ layer instead of the ITO/AZO stack electrode is illustrated.

as a valid alternative to SHJs, thanks to their improved thermal stability/compatibility with diffusion or firing processes.

Several papers [9]-[15] deal with solar cells featuring passivating contacts where the doped silicon layer is composed of poly-Si or $\mathrm{SiC}_{\mathrm{x}}$. In terms of efficiency two cell concepts stand out: 1) the combination of a diffused front emitter and a passivating rear contact (TOPCon) (25.7\%) [7], [8], 2) IBC featuring poly-Si/SiO $\mathrm{Sinctions}_{\mathrm{x}}(25.0 \%)$ [14]. Bifacial textured solar cell with tunnel oxide junction and doped a-Si thin-film emitter layers has been proposed by Silevo group [16] demonstrating efficiency above $23 \%$.

This paper, however, deals with a solar cell featuring poly-Si contacts on both sides. Possible advantages are: 1) a lean processing sequence without structuring processing, 2) high $V_{\mathrm{OC}}$ and fill factor (FF) due to passivating contacts (no selective emitter required to reach high $\left.V_{\mathrm{OC}} \mathrm{s}\right)$. Unfortunately, a limitation of poly-Si/ $\mathrm{SiO}_{\mathrm{x}}$ approach is the parasitic light absorption of the poly-Si layer, making the application of the front poly-Si/SiO potentially problematic [9]. Finally, poly-Si is commonly highly resistive. Carrier mobility is limited to a few tens $\mathrm{cm}^{2} / \mathrm{V} / \mathrm{s}$ dramatically affecting FF.

Poly-Si front and rear passivating contacts complemented by a TCO to provide sufficient lateral conductivity have been recently proposed [9] [see Fig. 1(a)]. For the sake of simplicity, 
in this paper we name such a solar cell poly-Si top/rear contacts. In [9], a p-type c-Si substrate was investigated. Since no front texturing was used, short-circuit current density $\left(J_{\mathrm{SC}}\right)$ is limited to approximately $33 \mathrm{~mA} / \mathrm{cm}^{2}$ and efficiency to $19 \%$. Feldmann et al. conclude that, although the realization of a poly- $\mathrm{Si} / \mathrm{SiO}_{\mathrm{x}}$ contact for both solar cell sides [see Fig. 1(a)] enhances $V_{\mathrm{OC}}$, the parasitic absorption and the resistivity of the poly-Si at the front are relevant factors, affecting $J_{\mathrm{SC}}$ and FF.

In this paper, by means of a simulation flow, we start from the architecture presented in [9] and propose substantial modifications in order to overcome its limitations. We adopt physical models calibrated by means of measurement performed on the poly-Si top/rear contacts solar cells fabricated at Fraunhofer ISE.

First, following [17], we account for a textured front surface and investigate the impact of front TCO presence and of front contact grid geometry on solar cell figures of merit (FOMs).

Second, a rear junction (RJ) design of the poly-Si top/rear contacts solar cell featuring a front surface field (FSF) implemented by adopting an n-type c-Si substrate is investigated [see Fig. 1(b)]. Such a structure leads to improved efficiency compared with the p-type poly-Si top/rear contacts front junction (FJ) solar cell counterpart. As a matter of fact, in the n-type substrate solar cell, the lateral carrier transport occurs mainly in the substrate and not in the top poly-Si layer, mitigating the impact of poly-Si resistivity on the FF.

In order to obtain better efficient tunneling effect, thanks to a stronger band bending in c-Si and, thus, lower contact resistivity, a higher doping value concentration of the front poly-Si layer is required. In [9], a lower passivation quality at the p-type poly$\mathrm{Si} / \mathrm{SiO}_{\mathrm{x}}$ interface with respect to n-type interface as well as a lower measured peak doping concentration for Boron profiles has been observed. This is consistent with the lower Boron solubility with respect to the Phosphorus one, although several research groups achieved similar contact resistivity [12], [14], [18] with heavily doped Boron poly-Si layers comparable to that obtainable by using Phosphorus [10], [19]-[21]. The physical parameters in our simulation work are calibrated on the basis of experimental conditions of [9], in which only phosphorus-doped poly-Si as front layer material is considered.

According to simulations, efficiency above $23 \%$ is possible with poly-Si top/rear contacts solar cells implementing RJ design, even without TCO. In addition, the sensitivity of FOMs on front poly-Si thickness and doping concentration is studied. Finally, the impact of $\mathrm{c}-\mathrm{Si} / \mathrm{SiO}_{\mathrm{x}}$ interfaces defectiveness and of the effective tunneling masses is investigated for the RJ design of the poly-Si top/rear contacts solar cell, by means of numerical simulations.

\section{Studied Devices And Simulation Methodology}

\section{A. Studied Devices}

The p-type $2 \mathrm{~cm}$ x $2 \mathrm{~cm}$ planar poly-Si top/rear contacts solar cell fabricated and experimentally characterized at Fraunhofer ISE [9], features poly-Si contacts at both front and rear side [see Fig. 1(a)]. The absorber is a 250- $\mu$ m-thick p-type 1 $\Omega$ cm float zone (FZ) Si wafer, and poly-Si(n)/poly-Si(p) contacts are present at the front- and rear-side, respectively. The
$\mathrm{SiO}_{\mathrm{x}}$ layer is $\sim 1.5 \mathrm{~nm}$ thick. Both poly-Si layers are $15 \mathrm{~nm}$ thick and doping concentrations, provided by electrochemical capacitance-voltage (ECV) measurements [9], are $4.10^{19} \mathrm{~cm}^{-3}$ for the poly-Si(n) and $2.10^{19} \mathrm{~cm}^{-3}$ for the poly-Si(p). Since the adopted thin poly-Si film exhibits a significant sheet resistance, in the order of $1000 \Omega / \mathrm{sq}$, the deposition of a TCO in the front is required. More in detail, the front stack consists of a 20-nm-thick atomic-layer-deposited Al-doped zinc oxide (AZO) interlayer and $55 \mathrm{~nm}$ sputtered indium tin oxide (ITO), reducing the sheet resistance down to $125 \Omega / \mathrm{sq}$ and avoiding sputter damage of the passivating contact.

The front grid includes $60 \mu \mathrm{m}$ wide and $2.5 \mathrm{~mm}$ thick fingers with $800 \mu \mathrm{m}$ spacing, realized by thermal evaporation of $\mathrm{Ti} / \mathrm{Pd} / \mathrm{Ag}$ and lift-off; the fully metalized rear side is coated by thermally evaporated $\mathrm{Ag}$.

Fig. 1(b) shows an additional structure that is analyzed in this paper by means of numerical simulations, the n-type poly-Si top/rear contacts solar cell (RJ design). In such case, an FSF structure is obtained, thanks to an n-doped poly-Si layer. In the sketch of Fig. 1(b), the emitter metal contacts directly the poly-Si and the front interface is coated by a $\mathrm{SiN}_{\mathrm{x}}$ layer.

Realistic contact resistivity $\left(\rho_{c}\right)$ values have been chosen for the mentioned structures. For the metal/ITO interface, we assumed a realistic $\rho_{c}$ of $0.1 \mathrm{~m} \Omega \cdot \mathrm{cm}^{2}$ for evaporated contact, even higher than the value reported in [22]. Regarding the metal/poly$\mathrm{Si}$ interface, we adopted a value of $1 \mathrm{~m} \Omega \cdot \mathrm{cm}^{2}$, of the same order of magnitude of that reported in [22] for metal/semiconductor interface.

\section{B. Simulation Methodology and Validation}

The optical and electrical simulations reported in this paper were performed by using Sentaurus SDevice [23], allowing the modeling of the carrier-selective contacts as already successfully performed in [24].

In the case of solar cells featuring planar front interface, the spatially resolved 1-D profile of the photo-generated electronhole pairs within the silicon obtained from the optical simulation is mapped onto the 2-D electrical mesh grid.

The optical simulations have been performed by means of a standard raytracer in combination with the transfer matrix method boundary conditions [23]. The optical properties of the ITO/AZO stack, as well as of the poly-Si layers, are experimentally measured. In order to model the typical roughness observed in the presence of the considered back interface stack (c-Si/SiO $/$ $/$ Poly-Si/Ag), a Phong diffusive boundary condition [25] has been adopted, as already successfully performed in [26]-[28]. The standard reference spectrum ASTM AM1.5G has been considered.

Free carrier absorption (FCA) effect [29] within the poly-Si layers has been properly accounted for into numerical simulations as a function of the doping concentration following [30]. FCA can also affect the ITO layer. The optical properties of the ITO fabricated by Fraunhofer ISE are comparable to those reported by Holman in [31] for carrier density concentrations from $10^{19}$ to $10^{20} \mathrm{~cm}^{-3}$. The absorption coefficients of such cases show a negligible FCA effect within ITO layer. In addition, 


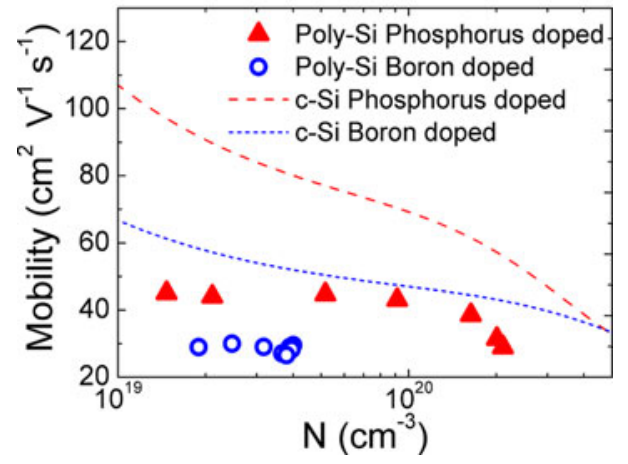

Fig. 2. Measured majority-carrier mobility values of the poly-Si layer as a function of the doping concentration $N$. Red-filled triangles and blue-open circles refer to Phosphorus-doped and Boron-doped poly-Si, respectively. The carrier mobility values of c-Si (red dashed-line: Phosphorus-doped; blue short dashed line: Boron-doped) are reported as references.

as demonstrated by simulations, although a single layer of ITO $(75 \mathrm{~nm})$ represents the state-of-the-art as TCO [22], the adopted double stack ITO/AZO does not introduce significant optical performance variations.

Regarding the electrical part, an analytical $0.1-\mu \mathrm{m}$ deep Gaussian profile (peak doping $10^{19} \mathrm{~cm}^{-3}$ ) adequately reproduces the doping tail of the poly-Si diffusions into the c-Si substrate, accordingly to the measured Phosphorus and Boron doping concentration profiles reported in [9]. The surface recombination velocity (SRV) value at both $\mathrm{c}-\mathrm{Si} / \mathrm{SiO}_{\mathrm{x}}$ interfaces has been calibrated in order to fit the experimental saturation current densities $\left(J_{0}\right)$ value reported in [9]: $\sim 5$ and $\sim 25 \mathrm{fA} / \mathrm{cm}^{2}$ for the front and back interface, respectively. The adopted SRV are of $800 \mathrm{~cm} / \mathrm{s}$ and $2.5 \cdot 10^{3} \mathrm{~cm} / \mathrm{s}$ for the front and back interface, respectively.

The doping-concentration-dependent majority carrier mobility for the Phosphorus- and Boron-doped poly-Si films are modeled according to the experimental values measured by Fraunhofer ISE. Fig. 2 reports such measured values as well as carrier mobility values of $\mathrm{c}-\mathrm{Si}$ for comparison. It is worth reporting that the poly-Si/SiO ${ }_{x}$ contacts of interests were realized by low-pressure chemical vapor deposited of a-Si layers, doping using ion implantation (Boron or Phosphorus) and subsequent annealing $\left(900{ }^{\circ} \mathrm{C}, 10 \mathrm{~min}\right)$, as treated in [9]. The measured majority carrier mobility of Phosphorus-doped Poly-Si deposited at Fraunhofer ISE plotted in Fig. 2 (grain size in the range from 100 to $400 \mathrm{~nm}$ for P-doped poly-Si) is comparable to those reported in the literature [32], [33] for a grain size of $122 \mathrm{~nm}$. Better poly-Si quality factor (i.e., larger grain size) may result in higher majority carrier mobility $\left(50-80 \mathrm{~cm}^{2} \mathrm{~V} / \mathrm{s}\right)$ [34], [35].

The electro-optical device simulations adopt up-to-date physical and electrical models (including doping and carrier density dependence of mobility, band-gap narrowing) reported in [22] and successfully used in other simulation studies [24], [26]-[28]. Regarding the Auger recombination, we use the parameterization proposed by Richter et al. [36]. We consider high-quality substrates in order to highlight the effects of the investigated designs. In detail, in our simulations, a Shockley Read Hall minority carrier lifetime of 7 and $4 \mathrm{~ms}$ has been adopted for n-type and p-type, respectively.

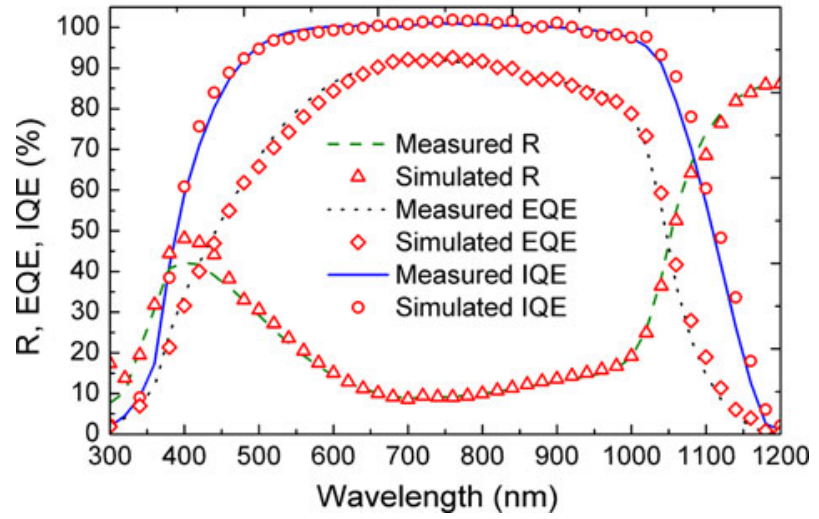

Fig. 3. Simulation results (open-red symbols) of reflectance $R$ (triangles), external quantum efficiency EQE (diamonds), and internal quantum efficiency (circles) as a function of the wavelength of the solar cell fabricated at Fraunhofer ISE. Lines refer to measured results [9].

We model the current flow through the tunnel oxide layers by using the nonlocal tunneling model similar to [24], not considering the case of mechanism governed by pinholes formation discussed in [37]. For electrons (holes) an effective tunneling mass $m_{t, e}\left(m_{t, h}\right)$ to $0.4 m_{0}\left(0.3 m_{0}\right)-\mathrm{m}_{0}$ electron rest massallows us to correctly fit the measured $I-V$ characteristic and FOMs of the cell.

The simulation models have been successfully validated by a comparison with experimental data as reported in Fig. 3, showing an excellent agreement between simulated and measured optical properties of the FJ solar cell.

\section{Modeling of the Textured Selective-Contact Solar Cell}

For all the studied structures of this paper (see Fig. 1) we assume a textured front surface to remove the main limitation to low $J_{\mathrm{SC}}$. To model the textured morphology, the spatially resolved optical generation rate was calculated starting from a 3-D symmetry element representing a regular upright pyramid featuring an opening angle of $70.5^{\circ}$. Tunnel $\mathrm{SiO}_{\mathrm{x}}$ layer is assumed to be conformal to the textured interface with uniform thickness throughout the structure. Nonuniformities of dielectric layer have been extensively studied in [37]. We model the textured solar cell in an effective way by simulating a 2-D planar solar cell instead of a more computationally demanding structure reproducing the pyramidal morphology. Specific tests showed that FOMs are hardly affected by such an approximation.

In order to account in an effective way for the surface area enlargement due to texturing, we use an enhancement factor of 1.73 [22] for the $\mathrm{SRV}$ at the front $\mathrm{c}-\mathrm{Si} / \mathrm{SiO}_{\mathrm{x}}$ interface.

In Table I, the measured and simulated FOMs and Poly$\operatorname{Si}(n)$ saturation current density $J_{0, P o l y-S i(n)}$ for the textured case compared with the planar one are reported. We note that texturing leads to higher $J_{\mathrm{SC}}$ respect to the planar case. This is ascribed to a lower reflectance obtained through overall the spectrum. However, due to the increased surface recombination, the $J_{0, P o l y-S i(n)}$ increases of $\sim 5 \mathrm{fA} / \mathrm{cm}^{2}$ for the textured solar cell. Therefore, the expected gain in terms of $V_{\mathrm{OC}}$, thanks to the elevated $J_{\mathrm{SC}}$, is almost entirely compensated due to higher $J_{0, P o l y-S i(n)}$. 
TABLE I

P-Type Poly-Si top/REar ContaCts SOlar CELl: MEASuREd [9] AND SIMULATED RESULTS

\begin{tabular}{lccccc}
\hline \hline Front Surface & $\begin{array}{c}J_{\mathrm{SC}} \\
\left(\mathrm{mA} / \mathrm{cm}^{2}\right)\end{array}$ & $\begin{array}{c}V_{\mathrm{OC}} \\
(\mathrm{mV})\end{array}$ & $\begin{array}{c}\mathrm{FF} \\
(\%)\end{array}$ & $\begin{array}{c}\text { Eff. } \\
(\%)\end{array}$ & $\begin{array}{c}J_{0, \text { Poly }-S i(n)} \\
\left(\mathrm{fA} / \mathrm{cm}^{2}\right)\end{array}$ \\
\hline $\begin{array}{l}\text { With TCO* } \\
\begin{array}{l}\text { Measured [9] } \\
\text { Planar }\end{array}\end{array}$ & 33.4 & 707.0 & 81.5 & 19.2 & 5 \\
$\begin{array}{l}\text { Simulated } \\
\text { Planar** }\end{array}$ & 33.4 & 706.0 & 81.5 & 19.2 & 6 \\
Textured & 37.4 & 706.8 & 81.4 & 21.5 & 11 \\
\hline \hline
\end{tabular}

* TCO electrode composed by $55 \mathrm{~nm}$ of ITO and $20 \mathrm{~nm}$ of AZO

** Simulation of the structure experimentally characterized [9].

\section{RESUlTS AND DISCUSSION}

\section{A. P-Type Substrate: Front Junction Design}

Numerical simulations were used to investigate the impact on the FOMs of the presence of ITO/AZO stack (TCO). Moreover, in some cases the TCO is replaced for $\mathrm{SiN}_{\mathrm{X}}$ layer and the metal fingers directly contact the poly-Si. In such cases, the adopted $\mathrm{SiN}_{\mathrm{x}}$ layer thickness has been determined in order to maximize the photon current absorbed in substrate.

First, a study of the solar cells FOMs sensitivity on $t_{\text {poly }}$ and on finger spacing ( $W_{\text {spacing }}$ ) is carried out. In particular, $t_{\text {poly }}$ has been assumed within the $15-60 \mathrm{~nm}$ range while $W_{\text {spacing }}$ from 800 to $1800 \mu \mathrm{m}$. Outside these ranges, a dramatic degradation of $J_{\mathrm{SC}}$ and of FF occurs. Two different realistic poly-Si(n) Phosphorus doping concentration $\left(N_{\text {poly }}\right)$ values have been considered: $4 \cdot 10^{19} \mathrm{~cm}^{-3}$ and $2.7 \cdot 10^{20} \mathrm{~cm}^{-3}$ [9], [30]. In addition, for all the discussed structures, the poly-Si(p) at the back is 15 $\mathrm{nm}$ thick and its Boron doping concentration is $2 \cdot 10^{19} \mathrm{~cm}^{-3}$. The SRV values at c- $\mathrm{Si} / \mathrm{SiO}_{\mathrm{x}}$ interfaces, which allow us the fitting of the experimental results $\left(t_{\text {poly }}=15 \mathrm{~nm}\right)$, are assumed constant for the $t_{\text {poly }}$ - range considered in this study (15 to $60 \mathrm{~nm}$ ). In fact, from [9] we can conclude that although a slight influence of $t_{\text {poly }}$ on implied- $V_{\mathrm{OC}}\left(i V_{\mathrm{OC}}\right)$ was observed (for $t_{\text {poly }}$ from 6 to $\left.34 \mathrm{~nm}\right), J_{0}$ depends on $t_{\text {poly }}$ only in the range of 5-10 nm. Moreover, recent data published in [30], show that the implied- $V_{\mathrm{OC}}$ (i.e., saturation current density $J_{0}$ ) is not affected by $t_{\text {poly }}$ up to $145 \mathrm{~nm}$. In this paper, in the absence of a clear understanding of relationship between $\mathrm{c}-\mathrm{Si} / \mathrm{SiO}_{\mathrm{x}}$ interface quality and poly-Si thickness, we assume constant SRV (see Section II-B).

In Fig. 4 , the calculated $J_{\mathrm{SC}}$ and $V_{\mathrm{OC}}$ values are shown as a function of $t_{\text {poly }}$. The p-type FJ solar cell with TCO represents the baseline case. More in detail, Fig. 4(a) and (b) reports the simulation results for $N_{\text {poly }}$ set to $4 \cdot 10^{19} \mathrm{~cm}^{-3}$, whereas Fig. 4(c) and (d) corresponds to $N_{\text {poly }}=2.7 \cdot 10^{20} \mathrm{~cm}^{-3}$. From Fig. 4 it can be observed that the TCO stack leads to degradation of $J_{\mathrm{SC}}$ and $V_{\mathrm{OC}}$ due to significant parasitic absorption. In fact, our calculations show that the parasitic absorption loss of the front contact stack (TCO and poly-Si(n) layers) for the TCO case is close to $1.2 \mathrm{~mA} / \mathrm{cm}^{2}$ for $t_{\text {poly }}=15 \mathrm{~nm}$, reducing to $0.9 \mathrm{~mA} / \mathrm{cm}^{2}$ as the TCO is omitted. Increasing $N_{\text {poly }}$ leads to a better high-low junction [38], resulting in lower recombination at the front interface. Therefore, $V_{\mathrm{OC}}$ and $J_{\mathrm{SC}}$ slightly increase with the doping despite higher FCA effect.

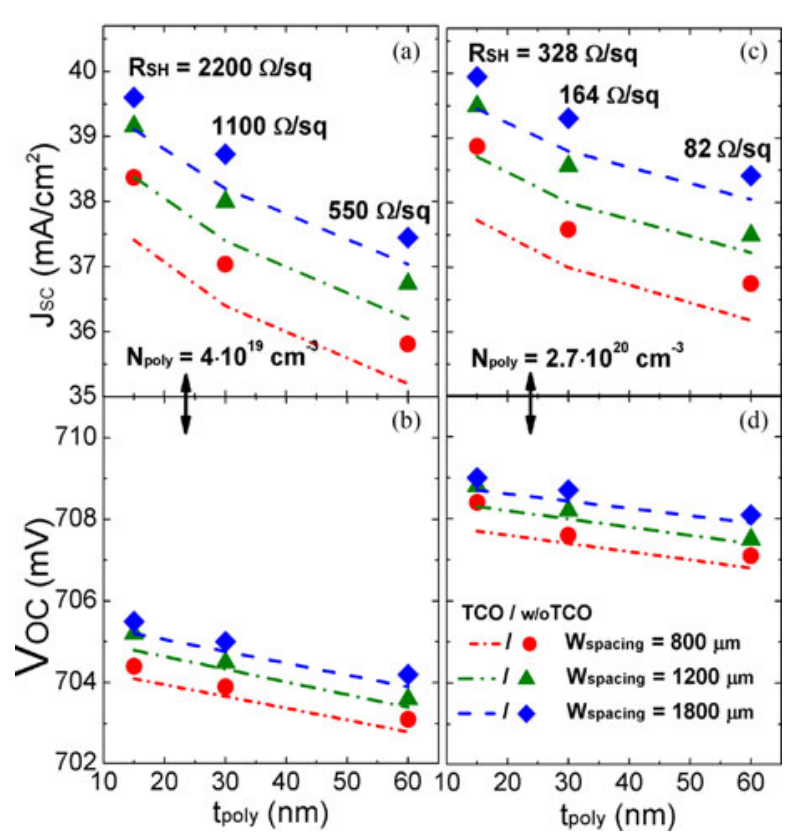

Fig. 4. Simulated short circuit current density $J_{\mathrm{SC}}$, (a) and (c), and open circuit voltage $V_{\mathrm{OC}},(\mathrm{b})$ and (d), as a function of the front poly-Si thickness $t_{\mathrm{poly}}$. (a) and (b) refer to a poly-Si doping concentration $N_{\text {poly }}$ of $4 \cdot 10^{19} \mathrm{~cm}^{-3}$ while (c) and (d) to a $N_{\text {poly }}$ of $2.7 \cdot 10^{20} \mathrm{~cm}^{-3}$. Lines denote the cases implementing the TCO electrode, whereas symbols refer to absence of TCO (w/oTCO). The colors blue, red, and green refer to a finger spacing $W_{\text {spacing }}$ of 800,1200 , and $1800 \mu \mathrm{m}$, respectively. For each $t_{\text {poly }}$, in (a) and (c) the sheet resistance $R_{\mathrm{SH}}$ value expressed in $\Omega /$ sq is reported.

As expected, larger finger distance decreases the front contact metal shading leading to higher $J_{\mathrm{SC}}$ (see Fig. 4).

Fig. 5 shows the simulated FF and efficiency values. It is clearly noticeable that the adoption of a high doping level allows for acceptable FF values $(>77 \%$ ) even without TCO; comparable FF-values can be obtained when TCO is present [see Fig. 5(c)], for poly-Si thickness above $30 \mathrm{~nm}$. In all other cases, in general avoiding TCO is dramatically detrimental to FF, especially for low poly-Si doping concentration $\left(N_{\text {poly }}=4 \cdot 10^{19} \mathrm{~cm}^{-3}\right)$ as illustrated in Fig. 5(a). Furthermore, $W_{\text {spacing }}$ is a relevant parameter affecting FF. When $N_{\text {poly }}=4 \cdot 10^{19} \mathrm{~cm}^{-3}$ removing the TCO electrode leads to degraded FOMs values for if $W_{\text {spacing }}>800 \mu \mathrm{m}$, mainly due to significant FF losses.

Our study demonstrates that for $t_{\text {poly }}=15 \mathrm{~nm}$ solar cells featuring TCO exhibit the highest conversion efficiency values. The simulated efficiencies without TCO are always lower than the results with TCO, especially for thin poly layers. As soon as $t_{\text {poly }}$ increases, the efficiency [see Fig. 5(b) and (d)] declines due to parasitic absorption losses within the front stack. In summary, the solar cells with TCO show higher $J_{\mathrm{SC}}$ losses but small FF losses while a tradeoff between the parasitic absorption losses and FF degradation exists for solar cells without TCO.

\section{B. N-Type Substrate: Rear Junction Design}

The lateral conductivity of the poly-Si(n) layer at the front side is one of the main reasons for the resistive losses observed in the studied FJ design of the poly-Si top/rear contacts solar cell especially when the poly-Si is highly resistive due to the limited 


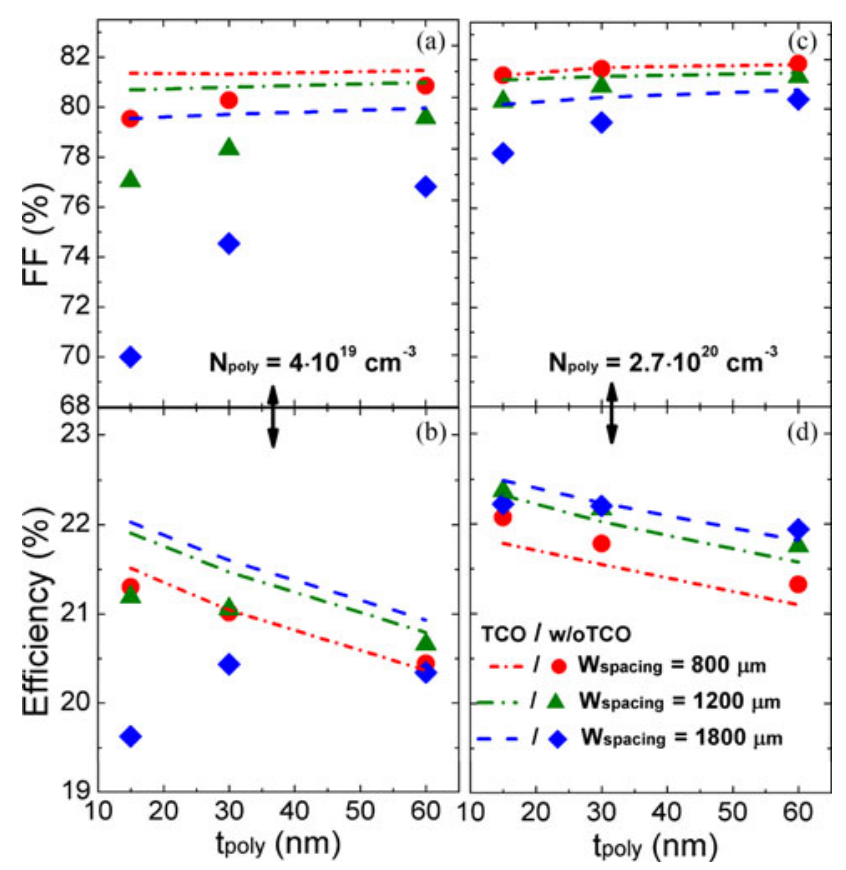

Fig. 5. Simulated fill factor FF, (a) and (c), and efficiency, (b) and (d), as a function of the front poly-Si thickness $t_{\text {poly }}$. (a) and (b) refer to a poly-Si doping concentration $N_{\text {poly }}$ of $4 \cdot 10^{19} \mathrm{~cm}^{-3}$ while (c) and (d) to a $N_{\text {poly }}$ of $2.7 \cdot 10^{20} \mathrm{~cm}^{-3}$. Lines denote the cases implementing the TCO electrode, whereas symbols refer to absence of TCO (w/oTCO). The colors blue, red, and green refer to a finger spacing $W_{\text {spacing }}$ of 800,1200 , and $1800 \mu \mathrm{m}$, respectively.

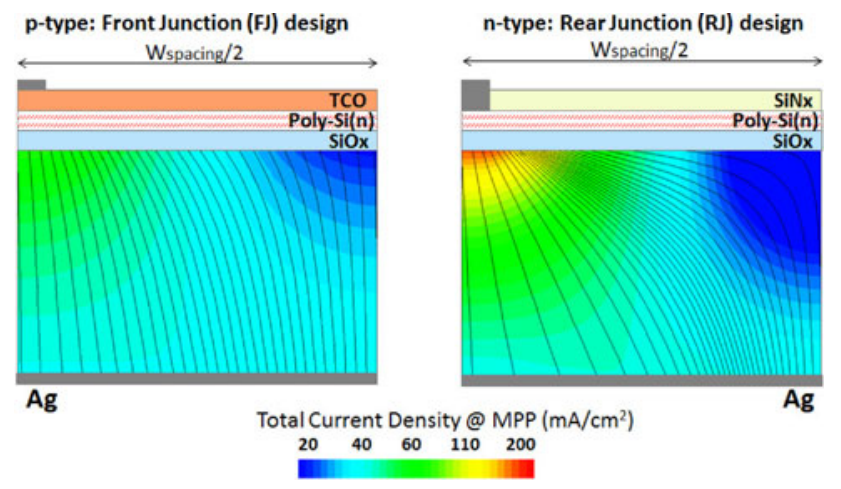

Fig. 6. Simulated current paths (lines) and total current densities (color map) within the absorber at MPP condition. Left: p-type poly-Si top/rear contacts solar cell (front junction FJ design); right: n-type (rear junction RJ design). The considered finger spacing $W_{\text {spacing }}$ is $800 \mu \mathrm{m}$ and the plotted front stacks are not in scale. (The reader is referred to the web version of this paper for the interpretation of the references to color).

carrier mobility (see Fig. 2). In this section, we propose a scheme that avoids the previously discussed limitations, the RJ design that basically implements an n-type substrate instead of a p-type substrate, as depicted in Fig. 1(b). As demonstrated in [5] for SHJs, in a design in which the emitter is located at the rear side of the cell, the FSF allows for the reduction of the overall sheet resistance $R_{\mathrm{SH}}$, thanks to the coupling of the front poly-Si(n) and of the absorber (n-type). Thus, the current flow pattern toward the front electrode is differently distributed. Fig. 6, compares the current flow at the maximum power point (MPP) of the ptype (FJ) and n-type (RJ) poly-Si top/rear contacts solar cells
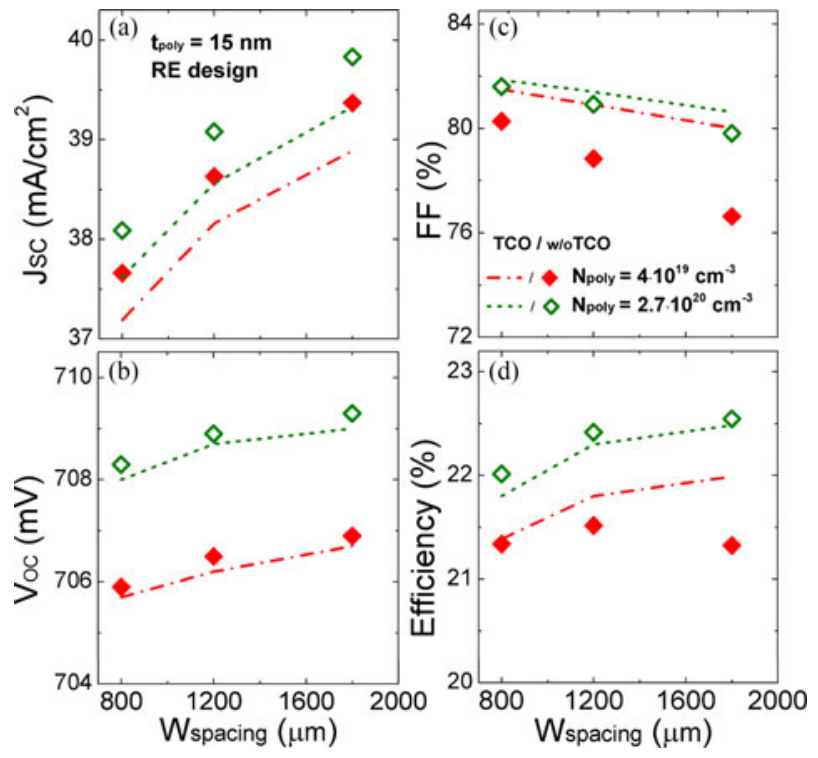

Fig. 7. Simulated short-circuit current density $J_{\mathrm{SC}}$ (a), open-circuit voltage $V_{\mathrm{OC}}(\mathrm{b})$, fill factor FF (c) and efficiency (d) as a function of the finger spacing $W_{\text {spacing }}$ for $\mathrm{n}$-type (RJ) design featuring front poly-Si thickness $t_{\mathrm{poly}}=$ $15 \mathrm{~nm}$. Filled and open symbols refer to a poly-Si doping concentration $N_{\text {poly }}$ of $4 \cdot 10^{19} \mathrm{~cm}^{-3}$ (red) and $2.7 \cdot 10^{20} \mathrm{~cm}^{-3}$ (green), respectively. Symbols and lines denote cases without TCO (w/o TCO) and with TCO, respectively.

for $W_{\text {spacing }}=800 \mu \mathrm{m}$. It can be clearly observed that in the RJ design a significant part of the transport occurs in the substrate, reducing the lateral transport contribution in the highly resistive front poly-Si.

In the following, RJ solar cells are simulated by assuming the same set of physical models and a 15-nm thick poly-Si(n) as top electrode of the FJ solar cells (see Section II-B)

In Fig. 7(a) and (b), $J_{\mathrm{SC}}$ and $V_{\mathrm{OC}}$ are reported as a function of finger spacing. We observe an $N_{\text {poly }}$ impact for RJ solar cells comparable to the one of FE (see Fig. 4).

The most interesting findings are those observable from Fig. 7(c) and (d). In Fig. 7(c), the FF gain obtained, thanks to the RJ design concept, is clearly noticeable. In particular, for $N_{\text {poly }}=2.7 \cdot 10^{20} \mathrm{~cm}^{-3}$ the sensitivity to TCO presence is reduced. Promising efficiency values around $22.5 \%$ are obtained [see Fig. 7(d)]. In contrast with the FJ design, these values can be achieved with and without a TCO.

As stated in Section II, the adopted contact resistivity values have been realistically assumed following [22]. Since the quality of the contact formation is process-dependent, we investigated the impact of front-contact $\rho_{c}$ on FOMs. Simulation results (not shown) demonstrate that the impact of $\rho_{c}$ on the solar cell FOMs is negligible for values $<10 \mathrm{~m} \Omega \cdot \mathrm{cm}^{2}$.

In this paper, the considered range of majority carrier mobility as a function of the doping concentration in poly-Si is considerably small (see Fig. 2). However, it is worth noting that a significant enlargement of the front poly-Si grain size could lead to higher majority carriers' mobility value, thus resulting in a reduced efficiency enhancement of RJ scheme compared with FJ. Overall, higher poly-Si carrier mobility leads to an increase in efficiency, thanks to lower resistivity. 


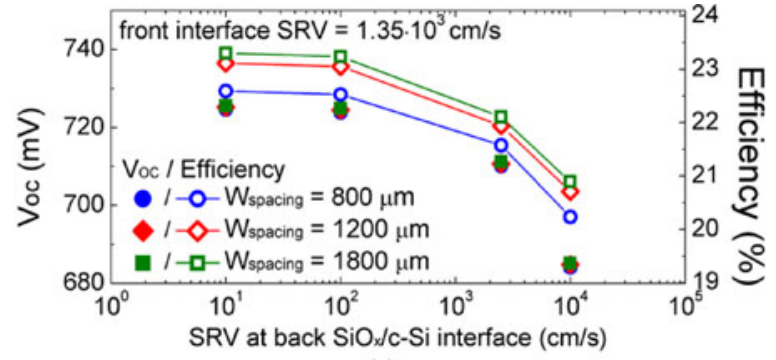

(a)

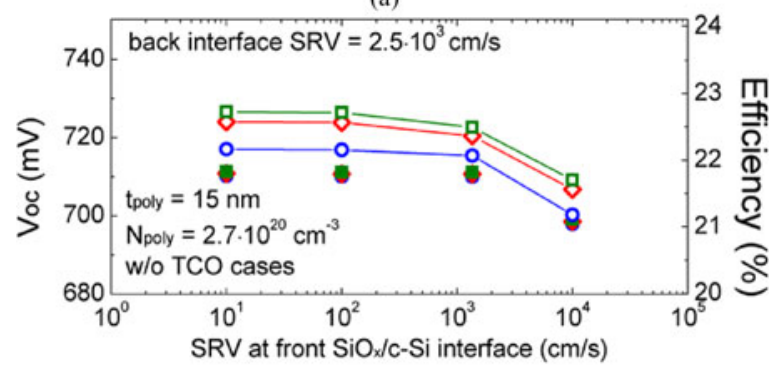

(b)

Fig. 8. Simulated open-circuit voltage $V_{\mathrm{OC}}$ (filled symbols) and efficiency (open symbols) for the n-type poly-Si top/rear contacts solar cell (RJ design) featuring poly-Si thickness $t_{\text {poly }}=15 \mathrm{~nm}$ and doping concentration $N_{\text {poly }}=$ $2.7 \cdot 10^{20} \mathrm{~cm}^{-3}$. In (a) and in (b) the values are plotted as a function of the back SRV and front SRV, respectively. The colors blue, red, and green refer to a finger spacing $W_{\text {spacing }}$ of 800,1200 , and $1800 \mu \mathrm{m}$, respectively.

\section{Rear Junction Design: Sensitivity to Interface Passivation}

In order to study the impact of defectiveness at the c$\mathrm{Si} / \mathrm{SiO}_{\mathrm{x}}$ interfaces on conversion efficiency, numerical simulations are performed. We limit the discussion to the RJ design, omitting TCO and assuming $t_{\text {poly }}=15 \mathrm{~nm}$ and $N_{\text {poly }}=$ $2.7 \cdot 10^{20} \mathrm{~cm}^{-3}$.

For the previous analyses, the SRV values at the c-Si/SiO $\mathrm{Sin}_{\mathrm{x}}$ terfaces determined on the basis of experimental data have been considered. However, simulations show that efficiency can be potentially improved considering realistic values of SRVs. With respect to SRV at front interface, $V_{\mathrm{OC}}$ improvements are negligible [see Fig. 8(a)]. Hence, from measurements, front interface exhibits good passivation [9]. On the contrary, concerning the back SRV, a significant increase in $V_{\mathrm{OC}}$ can be potentially attained. Assuming a better quality passivation of poly-Si/c-Si interfaces, conversion efficiency of $23.5 \%$ may be achieved.

\section{Influence of Effective Tunneling Mass $m_{t}$}

In previous sections, we adopted a value of electron (hole) tunneling effective mass $m_{t, e}\left(m_{t, h}\right)$ that successfully fits available experiments. In this paragraph, we study the sensitivity of the calculated solar cell FOM on $m_{t, e}$ and on $m_{t, h}$ by means of numerical simulations.

Fig. 9(a) shows the impact of $m_{t, e}$ on the FF for both ptype (FJ) and n-type (RJ) poly-Si top/rear contacts solar cells $\left(t_{\text {poly }}=15 \mathrm{~nm}, N_{\text {poly }}=2.7 \cdot 10^{20} \mathrm{~cm}^{-3}\right.$, TCO omitted, $m_{t, h}$ fixed at $\left.0.3 m_{0}\right)$. We observe that both the FJ and RJ scheme takes advantage of smaller $m_{t, e}$, thanks to a higher tunneling probability. In detail, resistive losses are reduced in RJ solar cell because, as previously discussed, a relevant part of the

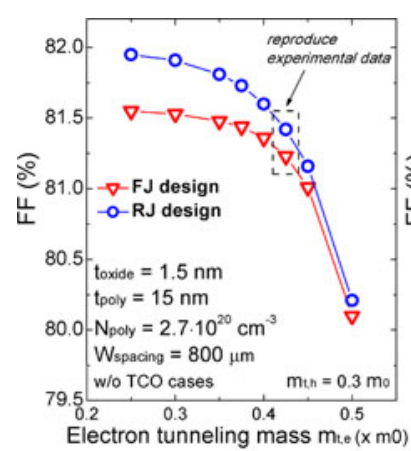

(a)

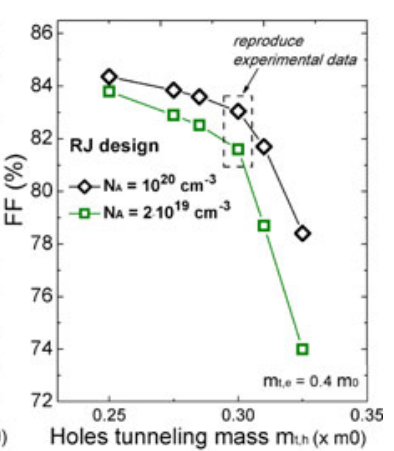

(b)
Fig. 9. Simulated FF against the effective electron tunneling mass $m_{t, e}$ (a) and the effective holes tunneling mass $m_{t, h}$ (b). In (a), red triangles and blue circles refer to p-type (FJ) and n-type (RJ) poly-Si top/rear contacts solar cell, respectively. In (b), black diamonds and green squares indicate a Boron doping concentration $N_{A}$ for the Poly-Si layer at the back side of $10^{20} \mathrm{~cm}^{-3}$ and of $2 \cdot 10^{19} \mathrm{~cm}^{-3}$, respectively. In (a) $m_{t, h}=0.3 m_{0}$ while in (b) $m_{t, e}=0.4 m_{0}$.

transport occurs in the substrate instead of within the highly resistive front poly-Si layer (see Fig. 6). On the contrary, a less effective tunneling mechanism $\left(m_{t, e}>0.4 m_{0}\right)$ decreases the difference in terms of FF between the two designs and the benefit introduced by $\mathrm{RJ}$ design are reduced. RJ design results more sensitive to the tunneling mechanism, due to its current transport path. However, if we consider a realistic $m_{t, e}$ range $(0.37-$ $\left.0.43 m_{0}\right) \mathrm{RJ}$ exhibits higher FF with respect to FJ scheme. The observed influence of $m_{t, e}$ can be compared with that reported in [24] for a solar cell featuring TOPCon. By exploring the same $m_{t, e}$ range (from $0.3 m_{0}$ to $0.45 m_{0}$ ) we can conclude that the sensitivity to such parameter is comparable $(\approx 0.6 \%$ abs of $\mathrm{FF}$ for FJ design). Moreover, it is worth reporting that in [24] the passivated contact (electrons as majority carriers) concept has been applied to a full-metalized back contact, whereas in this paper to a front contact.

The influence of $m_{t, h}$ concerns the tunneling mechanism at the full back-contacted side of the studied cells. Simulation results of Fig. 9(b) $\left(m_{t, e}\right.$ fixed at $\left.0.4 m_{0}\right)$ demonstrate that the RJ design is more sensitive to $m_{t, h}$ than to $m_{t, e}$ [shown in Fig. 9(a)]. In fact, for a relatively low Boron doping value concentration $\left(N_{A}\right)$ of the poly-Si(p) back layer, the tunneling mechanism is mainly governed by the assumed $m_{t, h}$ value. On the contrary, a higher $N_{A}$ leads to increased FF and to a less sensitivity to $m_{t, h}$. In addition, we observe a higher $V_{\mathrm{OC}}$, thanks to a better highlow junction effect. More in detail, for $m_{t, h}$ reproducing experimental data $(0.3 \mathrm{~m} 0)$, an efficiency increasing of $\sim 0.55 \%$ abs results by considering $N_{A}$ of $10^{20} \mathrm{~cm}^{-3}$.

\section{CONCLUSION}

In this paper, we presented a calibrated numerical simulation flow able to successfully model the solar cell fabricated by the Fraunhofer ISE featuring poly-Si/SiO $\mathrm{x}$ carrier-selective contact on both sides. In this study, we addressed the solar cell design to a scheme avoiding the TCO that leads to increase in manufacturing cost and process complexity. In the case of a FJ design of the solar cell with poly-Si top/rear contacts, we have observed that, although $J_{\mathrm{SC}}$ and $V_{\mathrm{OC}}$ benefit from the absence of TCO, 
FF is critically influenced by front electrode conductibility. FF degradation can be mitigated by increasing either the poly-Si layers thickness or doping concentration, but TCO is suggested to attain acceptable efficiency. Increased doping concentration in poly-Si may result both in a better high-low junction and in a decrease in resistive losses. To overcome the typical limitations of a FJ design, a RJ scheme is proposed. The presence of a FSF reduces the lateral transport in the front poly-Si layer, therefore, in case of sufficiently doped poly-Si, the RJ design is more insensitive to TCO properties with respect to the FJ design. This enables higher conversion efficiency combining the lower costs of an industrial type solar cell based on carrier-selective contacts. As shown by simulations, conversion efficiency above $23 \%$ is obtainable without considering further improvements deriving from using fine-line metallization technology as well as smart wire interconnection. Finally, we observed that the influence of the effective electron tunneling masses used for simulations is limited if a range of $0.37-0.43 m_{0}$ is considered, while the holes tunneling mechanism is strictly dependent on the poly-Si(p) doping concentration.

\section{ACKNOWLEDGMENT}

The authors would like to thank A. Barulin for measuring the carrier mobility values reported in Fig. 2.

\section{REFERENCES}

[1] M. Taguchi et al., "24.7\% record efficiency HIT solar cell on thin silicon wafer," IEEE J. Photovolt., vol. 4, no. 1, pp. 96-99, Jan. 2014.

[2] F. Feldmann et al., "Tunnel oxide passivated contacts as an alternative to partial rear contacts," Sol. Energy Mater. Sol. Cells, vol. 131, pp. 46-50, 2014.

[3] F. Feldmann et al., "Efficient carrier-selective p- and n-contacts for Si solar cells," Sol. Energy Mater. Sol. Cells, vol. 131, pp. 100-104, 2014.

[4] K. Masuko et al., "Achievement of more than 25\% conversion efficiency with crystalline silicon heterojunction solar cell," IEEE J. Photovolt., vol. 4, no. 6, pp. 1433-1435, Nov. 2014.

[5] M. Bivour et al., "Silicon heterojunction rear emitter solar cells: Less restrictions on the optoelectrical properties of front side TCOs," Sol. Energy Mater. Sol. Cells, vol. 122, pp. 120-129, 2014.

[6] A. Louwen et al., "A cost roadmap for silicon heterojunction solar cells," Sol. Energy Mater. Sol. Cells, vol. 197, pp. 295-314, 2016.

[7] S. W. Glunz et al., "The irresistible charm of a simple current flow pattern $-25 \%$ with a solar cell featuring a full-area back contact," in Proc. 31st Eur. PV Sol. Energy Conf. Exhib., Hamburg, Germany, 2015, pp. 259-263.

[8] A. Richter et al., "n-Type Si solar cells with passivating electron contact: Identifying sources for efficiency limitations by wafer thickness and resistivity variation," Sol. Energy Mater. Sol. Cells, vol. 173, pp. 96-105, 2017.

[9] F. Feldmann et al., "The application of poly-Si/SiOx contacts as passivated top/rear contacts in Si solar cells," Sol. Energy Mater. Sol. Cells, vol. 159, pp. 256-271, 2017.

[10] B. Nemeth et al., "Polycrystalline silicon passivated tunneling contacts for high efficiency silicon solar cells," J. Mater. Res., vol. 31, pp. 671-681, 2016.

[11] M. K. Stodolny et al., "n-Type polysilicon passivating contact for industrial bifacial n-type solar cells," Sol. Energy Mater. Sol. Cells, vol. 158, pp. 24-28, 2016.

[12] U. Römer et al., "Recombination behavior and contact resistance of $\mathrm{n}+$ and $\mathrm{p}+$ poly-crystalline Si/mono-crystalline Si junctions," Sol. Energy Mater. Sol. Cell, vol. 131, pp. 85-91, 2014.

[13] F. Feldmann et al., "Passivated rear contacts for high-efficiency n-type Si solar cells providing high interface passivation quality and excellent transport characteristics," Sol. Energy Mater. Sol. Cells, vol. 120, pp. 270274, 2014.
[14] M. Rienacker et al., "Junction resistivity of carrier-selective polysilicon on oxide junctions and its impact on solar cell performance," IEEE J. Photovolt., vol. 7, no. 1, pp. 11-18, Jan. 2017.

[15] Y. Tao et al., "730 mV implied Voc enabled by tunnel oxide passivated contact with PECVD grown and crystallized $\mathrm{n}+$ polycrystalline $\mathrm{Si}$," in Proc. 42nd IEEE Photovolt. Spec. Conf., New Orleans, LA, USA, 2015, pp. $1-5$.

[16] Heng et al., "> $23 \%$ High-efficiency tunnel oxide junction bifacial solar cell with electroplated Cu gridlines," IEEE J. Photovolt., vol. 5, no. 1, pp. 82-86, Jan. 2015.

[17] R. Peibst et al., "Implementation of $\mathrm{N}+$ and $\mathrm{P}+$ polo junctions on front and rear side of double-side contacted industrial silicon solar cells," in Proc. 32nd Eur. PV Sol. Energy Conf. Exhib, 2016, pp. 323-327.

[18] J. Y. Gan and R. M. Swanson, "Polysilicon emitters for silicon concentrator solar cells," in Proc. 21st IEEE Photovolt. Spec. Conf., Kissimmee, FL, USA, 1990, pp. 245-250.

[19] A. Das et al., "Boron diffusion with boric acid for high efficiency silicon solar cells\%," J. Electrochem. Soc., vol. 157, pp. 684-687, 2010.

[20] U. Römer et al., "Ion implantation for Poly-Si passivated back-junction back-contacted solar cells," IEEE J. Photovolt., vol. 5, no. 2, pp. 507-514, Mar. 2015.

[21] M. G. Young et al., Modeling of the hydrogen selective emitter for ntype silicon solar cells," in Proc. 42nd IEEE Photovolt. Spec. Conf., New Orleans, LA, USA, 2015, pp. 1-5.

[22] A. Fell et al., "Input parameters for the simulation of silicon solar cells in 2014," IEEE J. Photovolt., vol. 5, no. 4, pp. 1250-1263, Jul. 2015.

[23] Sentaurus TCAD, Release J-2014.09, Synopsys, Zürich, Switzerland.

[24] H. Steinkemper, F. Feldmann, M. Bivour, and M. Hermle, "Numerical simulation of carrier-selective electron contacts featuring tunnel oxides," IEEE J. Photovolt., vol. 5, no. 5, pp. 1348-1356, Sep. 2015.

[25] B. T. Phong, "Illumination of computer generated pictures," Commun. ACM, vol. 18, pp. 311-317, 1975.

[26] M. Zanuccoli et al., "Analysis of the impact of geometrical and technological parameters on recombination losses in interdigitated back-contact solar cells," Solar Energy, vol. 116, pp. 37-44, 2015.

[27] G. Paternoster et al., "Fabrication, simulation and experimental characterization of EWT solar cells with deep grooved base contact," IEEE J. Photovolt., vol. 6, no. 5, pp. 1072-1079, Sep. 2016.

[28] G. Paternoster et al., "Fabrication, characterization and modeling of a silicon solar cell optimized for concentrated photovoltaic applications, Sol. Energy Mater. Sol. Cells, vol. 134, pp. 407-416, 2015.

[29] S. C. Baker-Finch et al., "Near-infrared free carrier absorption in heavily doped silicon," J. Appl. Phys., vol. 116, 2014, Art. no. 063106.

[30] F. Feldmann et al., "Optical and electrical characterization of poly-Si/SiOx contacts and their implications on solar cell design," Energy Procedia, vol. 124, pp. 31-37, 2017.

[31] Z. Holman et al., "Infrared light management in high-efficiency silicon heterojunction and rear-passivated solar cells," J. Appl. Phys., vol. 113, 2013, Art. no. 013107.

[32] N. C.-C. Lu, L. Gerzberg, C.-Y. Lu, and J. D. Meindl, "A conduction model for semiconductor-grain-boundary-semiconductor barriers in polycrystalline-silicon films," IEEE Trans. Electron Devices, vol. 30 no. 2, pp. 137-149, Feb. 1983.

[33] S. Jin, "Boron activation and diffusion in polycrystalline silicon with flash-assist rapid thermal annealing," Ph.D dissertation, Univ. Florida, Gainesville, FL, USA, 2011

[34] B. Lombos et al., "Grain boundaries introduced deep levels in polysilicon," J. de Physique Colloques, vol. 43, pp. 199-206, 1982.

[35] A. Kumar et al., "Study of large-grained n-type polycrystalline silicon thin films made by the solid phase crystallization method," in Proc. 39th IEEE Photovolt. Spec. Conf., Tampa, FL, USA, 2013, pp. 586-588.

[36] A. Richter et al., "Improved quantitative description of Auger recombination in crystalline silicon," Phys. Rev. B, vol. 86, pp. 1-4, 2012.

[37] R. Peibst et al., "Working principle of carrier selective poly-Si/c-Si junctions: Is tunnelling the whole story?", Sol. Energy Mater. Sol. Cells, vol. 158, pp. 60-67, 2016.

[38] J. Del Alamo et al., "High-low junctions for solar cell applications," SolidState Electron., vol. 24, pp. 533-538, 1981.

Authors' photographs and biographies not available at the time of publication. 